\title{
SOME APPLICATIONS OF TANAHASHI'S RESULT ON THE BEST POSSIBILITY OF FURUTA INEQUALITY
}

\author{
MASAHIRO YANAGIDA
}

\begin{abstract}
We shall give some applications of Tanahashi's result which states the best possibility of Furuta inequality. Firstly, we shall discuss the best possibility of a well-known characterization of chaotic order: $\log A \geqslant \log B$ if and only if $A^{r} \geqslant\left(A^{\frac{r}{2}} B^{p} A^{\frac{r}{2}}\right)^{\frac{r}{p+r}}$ holds for all $p \geqslant 0$ and $r \geqslant 0$. Secondly, we shall discuss the best possibility of $p$-hyponormality of generalized Aluthge transformation $\tilde{T}_{S, t}=|T|^{S} U|T|^{t}$ for $p$-hyponormal or log-hyponormal operator $T$ whose polar decomposition is $T=U|T|$.
\end{abstract}

Mathematics subject classification (1991): 47B20, 47A63.

Key words and phrases: Furuta inequality, chaotic order, p-hyponormal operator, log-hyponormal operator, Aluthge transformation.

\section{REFERENCES}

[1] A. ALuthGE, On p-hyponormal operators for $0<p<1$, Integral Equations Operators Theory 13 (1990), 307-315.

[2] T. ANDO, On some operator inequalities, Math. Ann. 279 (1987), 157-159.

[3] M. FuJII, Furuta's inequality and its mean theoretic approach, J. Operator Theory 23 (1990), 67-72.

[4] M. FUJII, T. FURUTA AND E. KAMEI, Furuta's inequality and its application to Ando's theorem, Linear Algebra Appl. 179 (1993), 161-169.

[5] M. FuJII, J. F. JiANG AND E. KAMEI, Characterization of chaotic order and its application to Furuta inequality, Proc. Amer. Math. Soc. 125 (1997), 3655-3658.

[6] M. FuJII, J. F. JiAng AND E. KAMEI, A characterization of orders defined by $A^{\delta} \geqslant B^{\delta}$ via Furuta inequality, Math. Japon. 45 (1997), 519-525.

[7] M. FUJII, J. F. JIANG, E. KAMEI AND K. TANAHASHI, A characterization of chaotic order and a problem, J. Inequal. Appl. 2 (1998), 149-156.

[8] T. FURUTA, $A \geqslant B \geqslant 0$ assures $\left(B^{r} A^{p} B^{r}\right)^{1 / q} \geqslant B^{(p+2 r) / q}$ for $r \geqslant 0, p \geqslant 0, q \geqslant 1$ with $(1+2 r) q \geqslant p+2 r$, Proc. Amer. Math. Soc. 101 (1987), 85-88.

[9] T. FURUTA, An elementary proof of an order preserving inequality, Proc. Japan Acad. Ser. A Math. Sci. 65 (1989), 126.

[10] T. FURUTA, Applications of order preserving operator inequalities, Oper. Theory Adv. Appl. 59 (1992), $180-190$.

[11] T. FURUTA AND M. YANAGIDA, Further extensions of Aluthge transformation on p-hyponormal operators, Integral Equations Operator Theory 29 (1997), 122-125.

[12] T. HURUYA, A note on p-hyponormal operators, Proc. Amer. Math. Soc. 125 (1997), 3617-3624.

[13] E. KAMEI, A satellite to Furuta's inequality, Math. Japon. 33 (1988), 883-886.

[14] K. Tanahashi, Best possibility of the Furuta inequality, Proc. Amer. Math. Soc. 124 (1996), 141-146.

[15] K. TANAHASHI, The best possibility for the grand Furuta inequality (Japanese), Recent topics in operator theory concerning the structure of operators (Kyoto, 1996), RIMS Kōkyūroku 979 (1997), 1-14.

[16] K. TANAHASHI, On log-hyponormal operators, preprint.

[17] T. Yoshino, The p-hyponormality of the Aluthge transform, Interdiscip. Inform. Sci. 3 (1997), 91-93. 